\title{
BMJ Open Effects of reproductive period duration and number of pregnancies on midlife ECG indices: a secondary analysis from the Women's Health Initiative Clinical Trial
}

\author{
Nisha I Parikh, ${ }^{1}$ Kristopher Kapphahn, ${ }^{2}$ Haley Hedlin, ${ }^{2}$ Jeffrey E Olgin, ${ }^{1}$ \\ Matthew A Allison, ${ }^{3}$ Jared W Magnani, ${ }^{4}$ Kelli R Ryckman, ${ }^{5}$ Molly E Waring, ${ }^{6}$ \\ Marco Valentin Perez, ${ }^{7}$ Barbara V Howard ${ }^{8,9}$
}

To cite: Parikh NI, Kapphahn K, Hedlin $\mathrm{H}$, et al. Effects of reproductive period duration and number of pregnancies on midlife ECG indices: a secondary analysis from the Women's Health Initiative Clinical Trial. BMJ Open 2018;8:e019129. doi:10.1136/ bmjopen-2017-019129

- Prepublication history for this paper is available online. To view these files please visit the journal online (http://dx.doi. org/10.1136/bmjopen-2017019129).

Received 6 October 2017

Revised 30 May 2018

Accepted 29 June 2018

Check for updates

(C) Author(s) (or their employer(s)) 2018. Re-use permitted under CC BY-NC. No commercial re-use. See rights and permissions. Published by BMJ.

For numbered affiliations see end of article.

Correspondence to

Dr Nisha I Parikh;

parikh.nisha@gmail.com

\section{ABSTRACT}

Objectives Pregnancy, menses and menopause are related to fluctuations in endogenous sex hormones in women, which cumulatively may alter cardiac electrical conduction. Therefore, we sought to study the association between number of pregnancies and reproductive period duration (RD, time from menarche to menopause) with ECG intervals in the Women's Health Initiative Clinical Trials.

Design Secondary analysis of multicentre clinical trial. Setting USA.

Primary outcome measures ECGintervals: PR interval, P-wave duration, P-wave dispersion, QTc interval.

Participants $n=40687$ women (mean age $=62$ years) participating in the Women's Health Initiative Clinical Trials. $82.5 \%$ were white, $9.3 \%$ black, $4 \%$ Hispanic and $2.7 \%$ Asian.

Methods In primary analysis, we employed multivariable linear regression models relating number of pregnancies and $\mathrm{RD}$ with millisecond changes in intervals from enrolment ECG. We studied effect modification by hormone therapy use.

Results Among participants, $5+$ live births versus 0 prior pregnancies was associated with a $1.32 \mathrm{~ms}$ increase in PR interval $(95 \% \mathrm{Cl} 0.25$ to 2.38$)$, with a graded association with longer QTc interval (ms) (none (prior pregnancy, no live births) $=0.66$ ( -0.56 to 1.88$), 1=0.15(-0.71$ to 1.02$)$, $2-4=0.25(-0.43$ to 0.94$)$ and $5+$ live births $=1.15(0.33$ to 1.98$), p=0.008)$. RD was associated with longer $P R$ interval and maximum P-wave duration (but not P-wave dispersion) among never users of hormone therapy: (PR (ms) per additional RD year: 0.10 (0.04 to 0.16); higher P-wave duration (ms): 0.09 (0.06 to 0.12$)$ ). For every year increase in reproductive period, QTc decreased by $0.04 \mathrm{~ms}$ (-0.07 to -0.01$)$.

Conclusions An increasing number of live births is related to increased and $\mathrm{RD}$ to decreased ventricular repolarisation time. Both grand multiparity and longer $\mathrm{RD}$ are related to increased atrial conduction time. Reproductive factors that alter midlife cardiac electrical conduction system remodelling in women may modestly influence cardiovascular disease risk in later life.
Strengths and limitations of this study

- A notable limitation is that the exposure variables were acquired retrospectively.

- A strength is the use of a well-characterised multiethnic, large data set of postmenopausal women representative of women in the USA.

- We were unable to adjust for pregnancy complications such as pre-eclampsia or gestational diabetes.

Trial registration number NCT00000611; Post-results.

\section{INTRODUCTION}

ECG parameters reflect current as well as future cardiovascular disease risk

ECG parameters are reflections of both current and future cardiovascular disease (CVD) risk. For example, in the Framingham Heart Study, a prolonged PR interval ( $>200 \mathrm{~ms}$ ) (which is defined as the period, measured in milliseconds, that extends from the beginning of the $\mathrm{P}$ wave (the onset of atrial depolarisation) until the $\mathrm{R}$ wave), was related to incident atrial fibrillation, all-cause mortality and to the likelihood of needing a permanent pacemaker. ${ }^{1}$ In addition to PR interval, the P-wave duration (or the period in milliseconds during which the atrium depolarises) more directly relates to atrial size and is an antecedent of atrial fibrillation. ${ }^{2}$ Both PR interval and P-wave duration are markers of left atrial size which in turn is a correlate of hypertensive heart disease ${ }^{3}$ and incident stroke. ${ }^{4}$ P-wave dispersion, defined as the difference between the maximum and the minimum P-wave duration recorded from multiple different surface ECG leads, is an additional marker of atrial remodelling and 
antecedent of atrial fibrillation. ${ }^{5}$ It is unclear to what extent PR interval, P-wave duration or P-wave dispersion are affected by premenopausal hormonal fluctuations from the menstrual cycle and childbearing.

\section{Pregnancy, cardiac remodelling and the ECG}

Pregnancy and the postpartum period both have substantial physiological effects on cardiac electrophysiology. Physiological studies of women during early and late pregnancy as well as early post partum suggest a shortening of the corrected QT interval (QTc) which partially reverts back to pre-pregnancy values following post partum. ${ }^{67}$ The QT interval is defined as the measure of time between the onset of ventricular depolarisation and completion of ventricular repolarisation, and because QT interval is strongly related to heart rate, the QTc is corrected for heart rate. Direct pathophysiological links connecting myocardial structural remodelling and cardiac electrical remodelling have been increasingly recognised. ${ }^{8}$ With regards to myocardial remodelling, pregnancy-induced cardiac remodelling does not completely revert back to pre-pregnancy levels and effects of increasing parity on cardiac remodelling can be detected even in midlife. ${ }^{9}$ However, the extent to which an increasing number of pregnancies exerts long-lasting effects on the cardiac electrical conduction system is uncertain. ${ }^{9}$

\section{Oestrogen exposure and the ECG}

In addition to the more marked hormonal fluctuations seen during pregnancy, there are also more subtle, cyclic changes in oestrogen and progesterone cycling that occur during menstrual cycling in women of reproductive age. Testosterone and progesterone are recognised to decrease the QTC interval. ${ }^{10}$ Prior data from the Women's Health Initiative (WHI) Hormone Trial suggests that oestrogen-only postmenopausal therapy modestly prolongs QTc beyond that of both oestrogen-progestin therapy and placebo. ${ }^{11}$ However, it is uncertain whether the premenopausal endogenous hormonal fluctuations (reflected by the length of the interval from menarche to menopause, and by number of pregnancies) are associated with changes in QTc in the WHI.

WHI represents a unique resource to study questions related to pregnancy and reproductive history and ECG parameters and thus we sought to determine if there is a positive or negative association between number of pregnancies and reproductive period duration with midlife ECG intervals (PR interval and QTc) and P-wave parameters (P-wave maximum duration and dispersion).

\section{METHODS AND ANALYSIS PLAN}

Our current study design is a secondary analysis of a previously conducted set of clinical trials.

\section{Study sample}

The WHI recruitment began in 1991 and consisted of a set of clinical trials/andan observational study on

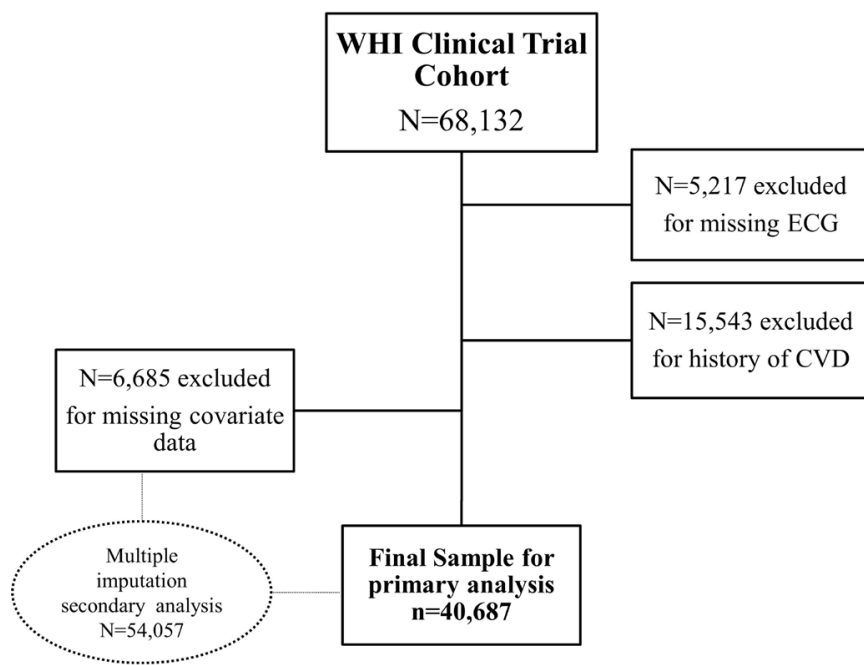

Figure 1 Creation of the study sample. Clinical trials include hormone trial, dietary modification and calcium/vitamin D. CVD, cardiovascular disease.

hormone therapy, dietary modification and calcium/ vitamin D supplementation on CVD, cancer and fractures. $^{12}$ The clinicaltrial.gov identifier for the WHI is NCT00000611. At the time of enrolment, all women enrolled in the WHI were required to be between 50 and 79 years of age, postmenopausal and intending to reside in the area for at least 3 years. Other enrolment criteria have been previously described. ${ }^{13}$ This analysis drew from the cohort of women enrolled in the WHI clinical trials (and not observational study), as WHI clinical trial participants have ECGs performed per protocol. Figure 1 shows the creation of the study sample. Of 68132 women in WHI studies (postmenopausal hormone therapy, diet and calcium/vitamin D and observational studies), we excluded 5217 who were missing ECGs and 15543 who had prevalent CVD. Because number of pregnancies and reproductive period (in particular age at menopause) are known to be associated with later CVD and a history of CVD is related strongly with ECG changes including QTc and certainly increased PR, we sought to exclude women with a history of CVD in order to assess associations between reproductive period duration and number of pregnancies that were not directly mediated through CVD. Of these 47372 women, 6685 were further excluded for having missing covariate data, leaving a final sample of included women equalling 40687 . In a missing imputation sensitivity analysis described below, we additionally analysed the 6685 women with missing covariate data (total $\mathrm{n}=54057$ ).

\section{Patient and public involvement}

WHI was designed to address the gaps in knowledge about the major health issues in postmenopausal women. Patients assisted research staff in recruiting, and results for all measures done at the study examinations were explained to each participant. Major study results are communicated to participants via newsletters. 


\section{Ascertainment of reproductive exposures}

Information on reproductive factors was collected via questionnaire at the second screening visit in the WHI (between 1993 and 1998). Participants were asked how many times they had been pregnant (were given choices ranging from 0 to $8+$ ), number of live births and how old they were at the end of the first and at the end of their last pregnancy $(<20,20-24,25-29,30-34,35$ +years $)$. In order to be able to also study women who had not experienced pregnancy and/or childbirth and in an effort to make our study as representative as possible, we separately categorised women who had had no prior pregnancies and women who had experienced a pregnancy but no live births (ie, due to miscarriage, stillbirth or abortion) as separate categories. We further categorised women based on our prior work demonstrating that having five or more pregnancies was associated with greater cardiac remodelling. ${ }^{9}$ Due to small cell sizes, we combined women with five or more pregnancies leading to live births into one category. Preliminary data analysis reflected that 2-4 had similar effects sizes for PR and QTc and thus these categories were collapsed into a single category for ease of interpretation. Therefore, the exposure categories for number of pregnancies leading to live births were as follows: no pregnancies (referent), none (prior pregnancy, no live births), 1, 2-4, 5 or more. Age at menarche $(<9,10,11,12,13,14,15,>16$ years $)$ and age at menopause was asked on this screening questionnaire. Reproductive period duration (RD) was defined as the duration between age at menarche to age at menopause (in years). Detailed current and prior hormone therapy (or postmenopausal hormone replacement therapy) usage and hysterectomy/oophorectomy status was collected at enrolment and has been previously described. ${ }^{14}$ Questions regarding the use and duration of oral contraceptive usage were also collected at enrolment.

\section{Ascertainment of covariates}

Age, income, education, self-reported race/ethnicity, geographic region of the USA, history and duration of breast feeding were collected at participant enrolment and second screening examinations. Body mass index (BMI, $\mathrm{kg} / \mathrm{m}^{2}$ ) was calculated using height and weight measured by study staff at baseline. Women with hypertension were identified as those with a self-reported history of treated hypertension or blood pressure measurements meeting JNC 7 criteria for hypertension. ${ }^{15}$ Diabetes was identified by self-reported use of antidiabetic medications and hyperlipidaemia by use of cholesterol-lowering medications.

\section{ECG parameters}

Standard 12-lead ECGs were recorded in all women by strictly standardised procedures in all clinical centres as has been described. ${ }^{16}$ All ECGs were processed in a central laboratory (EPICARE Center, University of Alberta, Edmonton, Canada, and later Wake Forest University, Winston-Salem, North Carolina, USA), where they were visually inspected for technical errors and inadequate quality. ECGs were processed with the 2001 version of the Marquette 12-SL program (GE Marquette). In addition to PR and QT intervals, we also examined the maximum P-wave duration and dispersion (from all 12 leads of the ECG). ${ }^{2}$ The QT interval was corrected using Bazett's formula.

\section{Statistical methods}

\section{Primary analysis}

We employed multivariable linear regression to assess the association between reproductive exposures (number of pregnancies and $\mathrm{RD}$ ) with the dependent variable of ECG parameters (PR interval in milliseconds, P-wave duration, P-wave dispersion, QTc in milliseconds). Multivariable models were adjusted for a priori covariates: age, BMI, hypertension status, diabetes, income, education, race/ethnicity, region, history of breast feeding, antianxiety medication, antidepressant medication, lipid medication, duration of breast feeding, oophorectomy status, hormone therapy use, heart rate and QRS duration. In analyses considering categories of live births, we employed a linear trend test.

We explored effect modification of the primary exposures, number of live births and RD, by hormone therapy usage and hysterectomy status. We classified hormone therapy usage into three categories: women who reported current, prior or no hormone therapy usage. A statistical interaction term between hormone therapy usage and the exposure (RD or number of live births) was used to consider effect modification by reported hormone therapy use. When the statistical interaction term was statistically significant $(\mathrm{p}<0.05)$ according to a likelihood ratio test, we presented the estimates in each of the three categories of hormone therapy use and we presented a single estimate if there was no evidence for effect modification by hormone therapy. A similar approach was employed for studying RD or number of live births and hysterectomy status. To show sensitivity of estimates to confounders, unadjusted associations were reported as well as those associations adjusted for the confounders listed above.

\section{Secondary analyses}

In secondary analyses, we removed subjects who reported never being pregnant and used multivariable linear regression to model associations between age at first live birth and the five ECG measures. These models used the same covariates to adjust association as those in our primary analyses. Subjects who had implausible secondary outcome values (ie, all zero values or all constant values across all ECG measures) were removed. We additionally adjusted for covariates that we were concerned may have confounded the associations between exposure and dependent variables in our study. We additionally fit additional models which included both RD and number of pregnancies to ensure that one exposure did not alter the other's association with the dependent variables. Given 
that anxiety and depression could affect both exposure and dependent variables in our study, we further adjusted for use of these medications. Antianxiety and antidepressant medication use (selective serotonin reuptake inhibitors (SSRIs) and non-SSRI) were recorded on enrolment by nurse examination of medication bottles. Medications were classified according to the National Drug Index classification system. We adjusted for $\mathrm{Ca} /$ vitamin $\mathrm{D}$ status, oral contraceptive usage (yes/no and duration or usage). We further adjusted for menstrual irregularities/fertility disorders/and endometriosis, which are also related to hormonal fluctuations in women.

\section{Multiple imputation analyses}

There were $\mathrm{n}=6685$ women in our study with missing covariate data. We used multiple imputation techniques to impute missing covariates and refit models from primary analyses to explore the sensitivity of our results to missing data. We used the PROC MI in SAS to construct 20 multiply imputed data sets. Missing variables were imputed via fully conditional specification method in PROC MI using all variables from the analytic model. We fit models to each imputed data set and pooled the results. The pooled results from imputation did not differ appreciably from the results of the complete case analysis (data not shown).

All analyses were performed in SAS V.9.4 (SAS Institute).

\section{RESULTS}

Table 1 shows the baseline characteristics of our sample including women who were included in our study and those excluded from analysis for missing variables. Data are displayed by number of pregnancies lasting at least 6 months. The mean age at enrolment was 62.4 years, while the mean age at menarche was 12.6 and mean age at menopause was 50.0 years. $82.5 \%$ of women were white, $9.3 \%$ black, $4 \%$ Hispanic and $2.7 \%$ Asian. Fortyfive per cent of the study sample reported never having used hormone therapy prior to enrolment.

\section{PR interval}

Compared with women reporting never having been pregnant, having five or more pregnancies was associated with a $1.3 \mathrm{~ms}$ longer PR interval (table 2). Among women who reported never having used hormones, each additional year of reported reproductive period duration was associated with a $0.1 \mathrm{~ms}$ longer PR interval (or atrial conduction velocity). Conversely, there was no significant association between RD and PR interval among women who reported prior or current hormone therapy use ( $p$ value for interaction $<0.01$ ) (table 2). Age at first live birth was not related to PR interval (data not shown).

\section{QTc}

Compared with never having been pregnant, having five or more pregnancies was related to a $1.2 \mathrm{~ms}$ longer QTc (table 3). However, not carrying a pregnancy to term, or having 1 or 2-4 term pregnancies (vs not being pregnant), were not related to QTc. For each additional year in reproductive period duration, there was a $0.4 \mathrm{~ms}$ shorter QTc (table 3). Restricting to women who had at least one live birth did not change our results (data not shown).

\section{P-wave duration and dispersion}

P-wave dispersion was higher for women with 2-4 live births (ms increase $=0.62,95 \%$ CI 0.01 to 1.24 ) and 5 live births $(0.94,95 \%$ CI 0.20 to 1.67$)$ compared with those who reported never having been pregnant (table 4). Reproductive period duration was related to maximum P-wave duration among women who reported never having used hormones $(0.09,95 \%$ CI 0.06 to 0.13$)$ but not among those who reported prior or current hormone therapy use ( $p$ interaction $<0.01)$ (table 5$)$.

\section{Secondary results}

Models that contained both RD and number of pregnancies together were not materially different (data not shown). Further adjustment for antidepressants and antianxiety medications did not materially affect our results. Further adjustment for Ca and vitamin D status or oral contraceptive use, and/or duration did not materially affect our results. Further adjustment for menstrual irregularities/fertility disorders/and endometriosis did not materially change our results.

\section{DISCUSSION}

\section{Summary of findings}

We found that having five or more pregnancies compared with none was associated with a small increase in midlife atrial conduction time, independent of factors known to be associated with this interval (PR). Number of live births among women with at least one live birth (compared with no prior pregnancies) was associated with increased atrial conduction time. Having five or more pregnancies was related to a small increase in ventricular repolarisation time compared with having no prior pregnancies. Among women reporting no prior exogenous hormone use, each additional year of reported RD was related to a very modest $(0.1 \mathrm{~ms})$ longer atrial conduction time. RD was related to a very modest increase in P-wave duration. RD was related to a shorter ventricular repolarisation time.

\section{Mechanisms linking pregnancy and atrial electrical remodelling}

The effect of cumulative pregnancies on midlife ECGs would likely result from both (1) the pregnancy itself and (2) incident cardiometabolic factors that are impacted by pregnancy such as adiposity ${ }^{17}$ and vascular stiffness, ${ }^{18}$ and premenopausal blood pressure. ${ }^{19}$ Adiposity and blood pressure are related to increased P-wave indices in a normal healthy population, ${ }^{20}$ and these $\mathrm{P}$-wave indices are ECG reflections of increased left atrial pressure, size and potentially fibrosis. The period of pregnancy and the peripartum are characterised by hormonal changes 


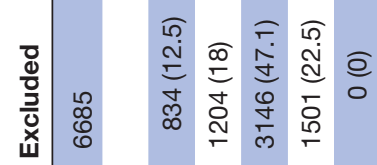

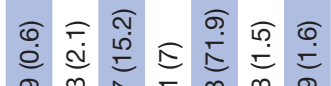

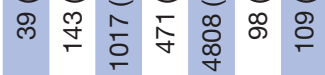

क के ल

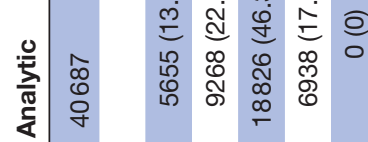

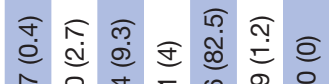

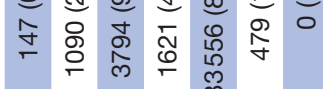

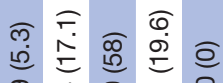

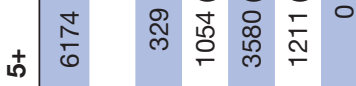

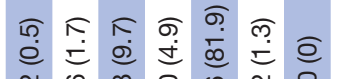

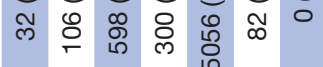

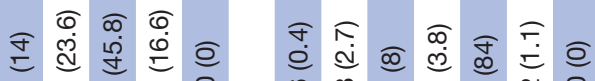

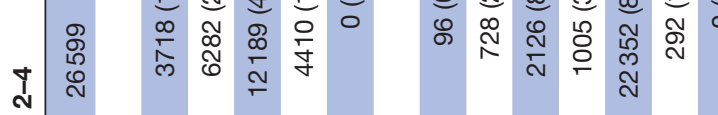

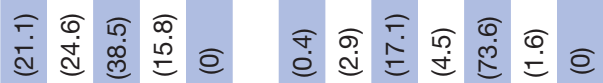

每

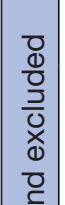

ติ

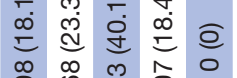

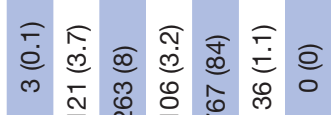

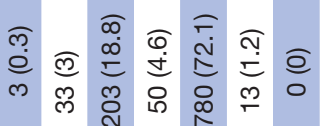

कृ

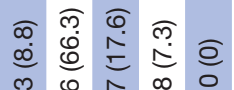

尔

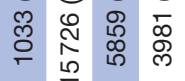

๓ 윙 ఠ유

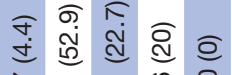

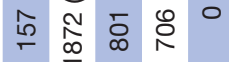

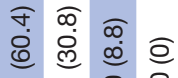

인 응 응

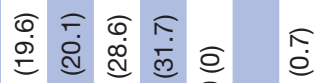

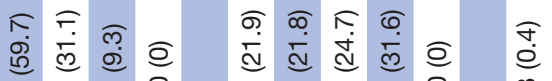

N

in $\infty$

㚙

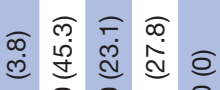

チ

ชิ สฺุ

मृ

गु ल्ల 응

กรกต ต

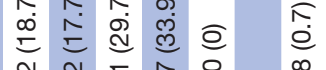

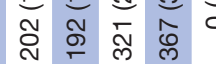

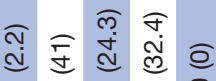

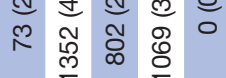

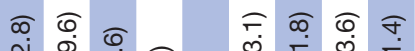

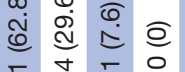

穴 交

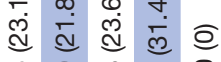

৫ำ

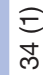




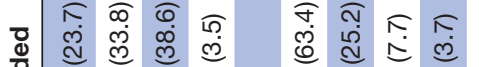

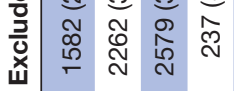

迥

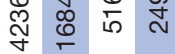

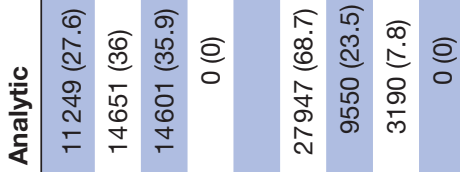

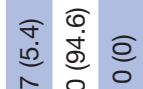

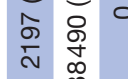

旁

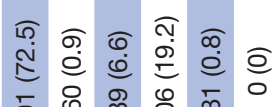

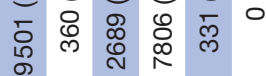

ลั

ำ

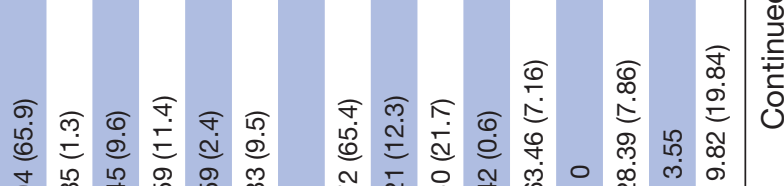

莳

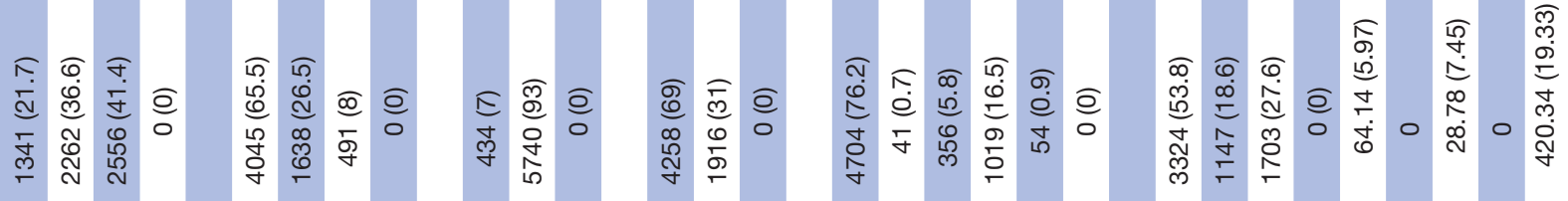
I

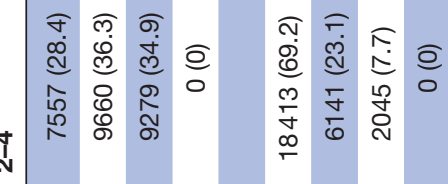

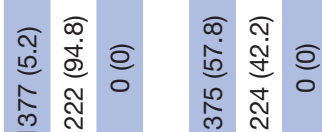

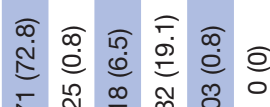

$\underset{\infty}{\widehat{\infty}}$

岕

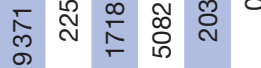

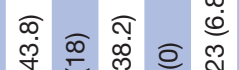

$\stackrel{\substack{n \\ \infty}}{\infty}$

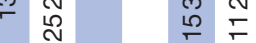

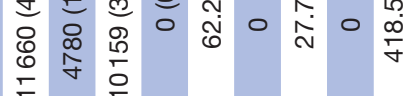

D

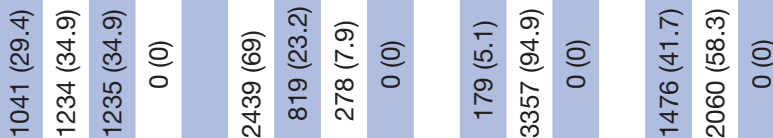

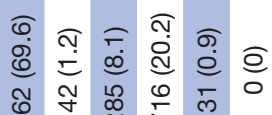

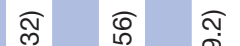

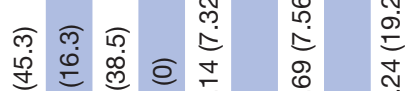

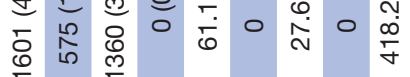

㐫

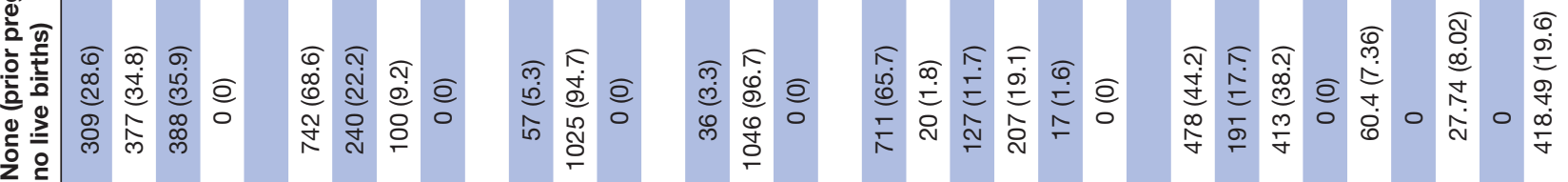

蒙

ธัซ ช ส

वे ल्ल ल्

¿্ঠ

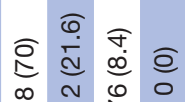

बิ

$\begin{array}{ll}\text { ลุ } \\ \stackrel{\infty}{\infty} & 0\end{array}$

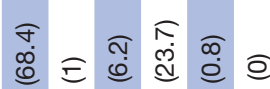

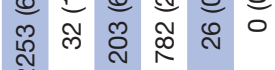

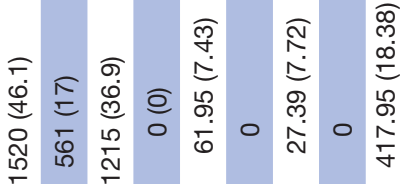
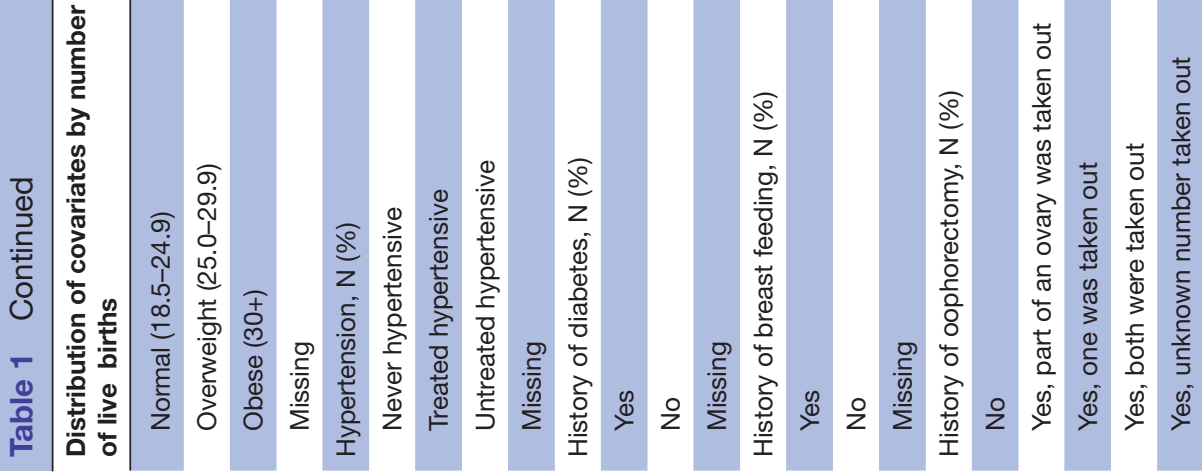

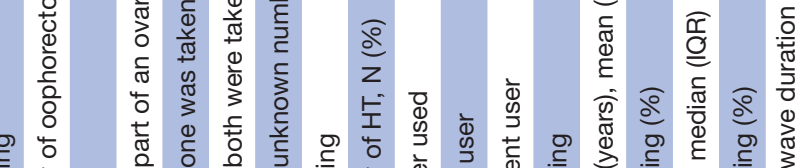

बิ

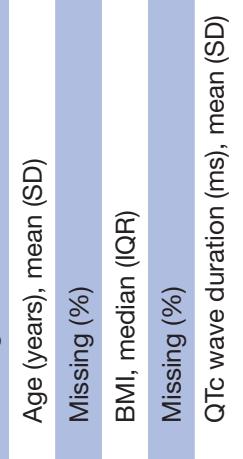




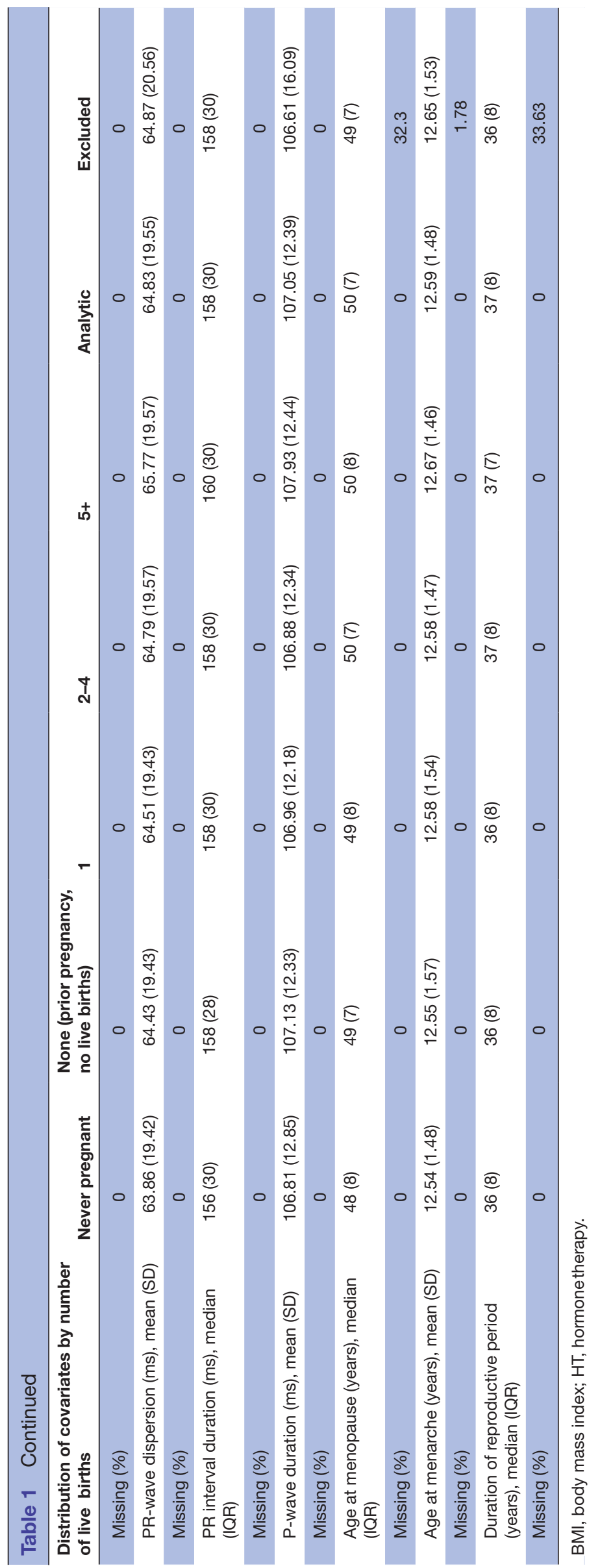

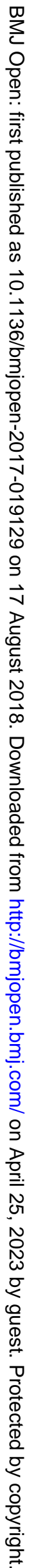


Table 2 Unadjusted and multivariable-adjusted association of number of pregnancies leading to live births and reproductive period duration with PR interval $(\mathrm{ms})$ in $\mathrm{n}=40687$ women in the Women's Health Initiative Clinical Trials

\section{Unadjusted \\ effect $(95 \% \mathrm{Cl})$ \\ Multivariable-adjusted \\ effect $^{*}(95 \% \mathrm{Cl})$}

Number of live births and reproductive period duration are each in their own separate multivariable models

Number of live births (categorical with never pregnant as

referent category)

$\begin{array}{lll}\text { Never pregnant } & \text { Ref. } & \text { Ref. } \\ \text { None (prior pregnancy, no live births) } & 1.44(-0.18 \text { to } 3.06) & 1.15(-0.43 \text { to } 2.74) \\ 1 & 1.16(0.04 \text { to } 2.28) & 0.54(-0.57 \text { to } 1.66) \\ 2-4 & 1.20(0.34 \text { to } 2.05) & 0.59(-0.301 \text { to } 1.48) \\ 5+ & 3.06(2.07 \text { to } 4.06) & 1.32(0.25 \text { to } 2.39)\end{array}$

Due to the fact that there was statistically significant effect modification by HT use on the association between reproductive period and PR interval in linear regression models, we present the model estimates by strata of HT use

\begin{tabular}{lll} 
Reproductive period duration (continuous, years) & & \multicolumn{1}{c}{$\begin{array}{c}\text { P value for } \\
\text { interaction=0.009 }\end{array}$} \\
Never HT user & $0.05(-0.01$ to 0.11$)$ & $0.10(0.04$ to 0.16$)$ \\
Past HT use & $0.002(-0.07$ to 0.08$)$ & $0.08(-0.00$ to 0.15$)$ \\
Current HT use & $-0.09(-0.15$ to to 0.03$)$ & $-0.02(-0.08$ to 0.04$)$
\end{tabular}

${ }^{*}$ Covariates include age, baseline BMI, baseline hypertension status, history of diabetes, income, education, race/ethnicity, region, history/ duration of breast feeding, lipid medication, oophorectomy status, hysterectomy status, hormone use history, heart rate and QRS duration. BMI, body mass index; HT, hormone therapy.

that affect both cardiovascular haemodynamics and adaptive myocardial remodelling. ${ }^{21}$ Pregnancy causes increased cardiac output, increased left ventricular mass and decreased systemic vascular resistance. ${ }^{22}$ The uterus and placenta in support of the growing fetus and fetal circulatory system represent a significant vascular shunt which contributes to these haemodynamic adaptations in pregnancy. ${ }^{22}$ The sum of these changes results in both left atrial and left ventricular dilation. However, the effects of normal pregnancy on electrographic remodelling during pregnancy are not well described. A prior small clinical study has looked at P-wave duration and P-wave dispersion among pregnant women compared with controls and found that both of these parameters are increased. ${ }^{23}$

\section{Pregnancy and cumulative effects on ventricular repolarisation}

A prior study in 37 women in late pregnancy compared with 18 age-matched controls demonstrated that QTc substantially prolongs late in pregnancy and that this only partially

Table 3 Unadjusted and multivariable-adjusted association of number of pregnancies leading to live births and reproductive period duration with QTc interval (ms) in $n=40687$ women in the Women's Health Initiative and Clinical Trials

$\begin{array}{ll}\text { Unadjusted } & \text { Multivariable-adjusted } \\ \text { effect }(95 \% \mathrm{Cl}) & \text { effect }^{\star}(95 \% \mathrm{Cl})\end{array}$

Number of live births and reproductive period duration are each in their own multivariable models

Number of live births (categorical with

never pregnant as referent category)

\begin{tabular}{lll} 
Never pregnant & Ref. & Ref. \\
\hline None (prior pregnancy, no live births) & $0.54(-0.76$ to 1.83$)$ & $0.66(-0.56$ to 1.88$)$ \\
1 & $0.29(-0.60$ to 1.18$)$ & $0.15(-0.71$ to 1.02$)$ \\
$2-4$ & $0.63(-0.05$ to 1.31$)$ & $0.25(-0.43$ to 0.94$)$ \\
$5+$ & $2.39(1.59$ to 3.19$)$ & $1.15(0.33$ to 1.98$)$ \\
Reproductive period duration (continuous, years) & $-0.09(-0.12$ to 0.06$)$ & $-0.04(-0.07$ to 0.01$)$ \\
\hline
\end{tabular}

${ }^{*}$ Covariates for number of live births analysis include age, baseline BMI, baseline hypertension status, history of diabetes, income, education, race/ethnicity, region, history/duration of breast feeding, lipid medication, oophorectomy status, hysterectomy status, hormone use history, heart rate and QRS duration. Covariates for reproductive period duration analysis include live births, age, baseline BMI, baseline hypertension status, history of diabetes, income, education, race/ethnicity, region, history of breast feeding, duration of breast feeding, lipid medication, oophorectomy status, hysterectomy status, hormone use history and QRS duration.

BMI, body mass index; HT, hormone therapy. 
Table 4 Unadjusted and multivariable-adjusted associations between number of pregnancies leading to live births with $\mathrm{P}$-wave duration and P-wave dispersion in $\mathrm{n}=39338^{*}$ women in the Women's Health Initiative and Clinical Trials

\begin{tabular}{|c|c|c|c|c|}
\hline Dependent variable & $\begin{array}{l}\text { Number of } \\
\text { live births }\end{array}$ & $\begin{array}{l}\text { Unadjusted } \\
\text { effect }(95 \% \mathrm{Cl})\end{array}$ & $\begin{array}{l}\text { Adjusted } \\
\text { effect }(95 \% \mathrm{Cl})\end{array}$ & $P$ values \\
\hline \multirow[t]{6}{*}{ P-wave duration (ms) } & & & & $\begin{array}{l}P \text { value for linear trend } \\
=0.73\end{array}$ \\
\hline & Never pregnant & Ref. & Ref. & \\
\hline & $\begin{array}{l}\text { None (prior pregnancy, } \\
\text { no live births) }\end{array}$ & $0.09(-0.73$ to 0.92$)$ & $0.09(-0.69$ to 0.87$)$ & \\
\hline & 1 & $-0.06(-0.63$ to 0.51$)$ & $-0.20(-0.76$ to 0.35$)$ & \\
\hline & $2-4$ & $-0.03(-0.47$ to 0.40$)$ & $-0.26(-0.70$ to 0.18$)$ & \\
\hline & $5+$ & 0.99 (0.49 to 1.50$)$ & $-0.22(-0.74$ to 0.31$)$ & \\
\hline \multirow[t]{6}{*}{ P-wave dispersion (ms) } & & & & $P$ for linear trend $=0.13$ \\
\hline & Never pregnant & Ref. & Ref. & \\
\hline & $\begin{array}{l}\text { None (prior pregnancy, } \\
\text { no live births) }\end{array}$ & $0.67(-0.42$ to 1.77$)$ & $0.64(-0.45$ to 1.72$)$ & \\
\hline & 1 & $0.44(-0.32$ to 1.20$)$ & $0.34(-0.42$ to 1.11$)$ & \\
\hline & $2-4$ & 0.72 (0.15 to 1.30$)$ & 0.62 (0.01 to 1.24$)$ & \\
\hline & $5+$ & 1.49 (0.82 to 2.17$)$ & 0.94 (0.20 to 1.67$)$ & \\
\hline
\end{tabular}

Effect estimates correspond to expected millisecond increase in the specified interval measure for each parity group relative to the never pregnant group. Fully adjusted models were adjusted for age, baseline BMI, baseline hypertension status, history of diabetes, income, education, race/ethnicity, region, history of breast feeding, antianxiety medication, antidepressant medication, lipid medication, duration of breast feeding, oophorectomy status, hysterectomy status, hormone use history, heart rate and QRS duration.

*n differs from main analyses due to the exclusion of women with implausible PR wave measures.

BMI, body mass index.

corrects back to pre pregnancy values post partum. ${ }^{7}$ Our finding that having five or more pregnancies compared with no prior pregnancies suggests that QTc prolongation during pregnancy may accumulate across successive pregnancies and will be significantly increased on midlife ECG. Furthermore, we found evidence for a doseresponse relationship between number of pregnancies and midlife QTc. Cardiac electrical remodelling often reflects myocardial remodelling. We previously demonstrated that an increasing number of pregnancies were related to left ventricular volume increase and increase in left ventricular mass in a multiethnic cohort of women. ${ }^{9}$ The increase in cardiac volume and mass were more marked in grand multipara's or women who had five or more pregnancies leading to live births. ${ }^{9}$ It is important to note that grand multiparity is less common with declining parity levels in the USA.

Table 5 Reproductive duration and P-wave duration and dispersion by hormone use status in $n=31538^{*}$ women in the Women's Health Initiative Clinical Trial

\begin{tabular}{|c|c|c|c|c|}
\hline Dependent variable & Hormone use status & $\begin{array}{l}\text { Unadjusted } \\
\text { effect }(95 \% \mathrm{Cl})\end{array}$ & $\begin{array}{l}\text { Adjusted } \\
\text { effect }(95 \% \mathrm{Cl})\end{array}$ & P values \\
\hline \multicolumn{5}{|c|}{$\begin{array}{l}\text { Due to the fact that there was statistically significant effect modification by HT use on the association between reproductive } \\
\text { period and P-wave duration in linear regression models, we present the model estimates by strata of HT use }\end{array}$} \\
\hline \multirow[t]{3}{*}{ P-wave duration (ms) } & Never user & 0.07 (0.03 to 0.11$)$ & 0.09 (0.06 to 0.13$)$ & \multirow{3}{*}{$\begin{array}{l}P \text { value for interaction }= \\
0.0009\end{array}$} \\
\hline & Past & $-0.04(-0.08$ to 0.005$)$ & $0.01(-0.03$ to 0.05$)$ & \\
\hline & Current & $-0.03(-0.06$ to 0.004$)$ & $0.01(-0.02$ to 0.05$)$ & \\
\hline \multirow[t]{3}{*}{ P-wave dispersion (ms) } & Never user & $0.002(-0.04$ to 0.05$)$ & $0.01(-0.03$ to 0.06$)$ & \multirow{3}{*}{$\begin{array}{l}\text { P value for interaction }= \\
0.65\end{array}$} \\
\hline & Past & $-0.03(-0.09$ to 0.02$)$ & $-0.01(-0.06$ to 0.05$)$ & \\
\hline & Current & $-0.04(-0.08$ to 0.003$)$ & $-0.02(-0.06$ to 0.03$)$ & \\
\hline
\end{tabular}

Effect estimates correspond to expected milliseconds increase in PR measure. These models contained an interaction term for reproductive period duration hormone use status. Fully adjusted models were adjusted for number of live births, age, baseline BMI, baseline hypertension status, history of diabetes, income, education, race/ethnicity, region, history of breast feeding, duration of breast feeding, antianxiety medication, antidepressant medication, lipid medication, oophorectomy status, hysterectomy status, hormone use history, heart rate and QRS duration.

${ }^{*} n$ differs from main analyses due to the exclusion of women with implausible PR-wave measures.

BMI, body mass index; HT, hormone therapy. 


\section{Reproductive period duration and atrial conduction}

The menstrual cycle consists of a relatively well-described hormone cycling in women consisting of both oestrogen and progesterone as well as testosterone production. A longer reproductive period duration reflects the cumulative exposure that a woman has to these endogenous fluctuations in sex hormone levels. Indeed, prior studies have assessed P-wave parameters throughout the menstrual cycle and noted that P-wave duration is substantially increased in the luteal phase. ${ }^{24}$ Among women who did report taking prior hormone therapy, we observed a very modest but significant increase in midlife PR interval and in P-wave duration. Exogenous hormone therapy use may obscure the relationship between endogenous hormone exposure from a longer reproductive period duration and $\mathrm{P}$-wave parameters, which would explain our findings of effect modification by hormone therapy use. An earlier age at menarche (which would be related to increased reproductive period duration) has been associated with increased adiposity ${ }^{25}$ and diabetes, ${ }^{26}$ which in turn have been linked with increased P-wave duration ${ }^{2}$ and, in the case of BMI, with increased left atrial remodelling ${ }^{27}$ and thus may also partially underlie our findings.

\section{Reproductive duration and decrease ventricular repolarisation time}

The QTc is shortened by the action of progesterone and lengthened by oestrogen during normal menstrual cycling. The net effect of these changes during a single menstrual cycle can result in shortening of ventricular repolarisation time or QTc. ${ }^{28}$ This is consistent with our finding that an incresed reproductive duration was modestly inversly related to QTc in WHI. Underlying these findings may be that increasing exposure to progesterone, in particular during menstrual cycling, may have cumulative and measurable effects on the midlife ECG in women.

\section{Clinical relevance of our findings}

The PR interval normally ranges from 120 to $200 \mathrm{~ms}$ in duration. Therefore, our finding that having five or more live births versus never having been pregnant was associated with an adjusted increase in PR interval of $1.32 \mathrm{~ms}$, has modest clinical significance. For an individual with a PR interval at the upper limits of normal, $1.32 \mathrm{~ms}$ may be more clinically relevant in terms of the increased risks of later CVDs with PR >200 ms. ${ }^{1}$ The association of number of pregnancies leading to live births with QTc (with five or more pregnancies leading to live births having a 1.15 ms increase in QTc compared with nulligravid women) is similarly modest with a normal QTc ranging from $~ 350$ to $460 \mathrm{~ms}$ in women. The effect sizes for reproductive duration were even more modest in size than those for P-wave indices and therefore likely have more relevance in terms of uncovering novel biological mechanisms related to cardiac electrical remodelling rather than reflecting clinically significant differences among individuals.

\section{Strengths and limitations}

The use of a well-characterised multiethnic, large data set of postmenopausal women representative of women in the USA is a strength of our study. A notable limitation is potential recall bias since the exposure variables were acquired retrospectively and some are very distant events (eg, age at menarche occurred $40-70$ years in the past). We were unable to adjust for pregnancy complications such as pre-eclampsia or gestational diabetes since these were not collected. We did not adjust for smoking, physical activity and habitual consumption of alcohol and coffee which may have been related to the exposure variables but are not widely known to be related to the ECG-dependent variables studied. We studied number of pregnancies in a categorical fashion and were unable, due to data constraints, to look at number of pregnancies as a continuous variables.

\section{Directions for future research}

Future studies that disentangle specific hormonal and molecular mechanisms that underlie the association demonstrated in our study will help us better understand our study findings. Understanding which specific fertility factors alter electrical remodelling in women is an important direction for future research.

\section{Conclusions}

We found that having five or more pregnancies leading to live births compared with never having been pregnant is related to small but significant changes in atrial conduction time and ventricular repolarisation time. A longer reproductive period duration in women not exposed to exogenous hormone therapy is related to a modest increase in atrial conduction time and to a modest decrease in ventricular repolarisation. Reproductive health factors reflective of endogenous sex hormone exposure may be significant determinants of cardiac electrical remodelling in midlife.

\section{Author affiliations}

${ }^{1}$ Division of Cardiology, University of California San Francisco, San Francisco, California, USA

${ }^{2}$ Quantitative Sciences Unit, Department of Medicine, Stanford University School of Medicine, Stanford, California, USA

${ }^{3}$ Department of Family Medicine, University of California, San Diego, San Diego, California, USA

${ }^{4}$ Division of Cardiology, Boston University School of Medicine, Boston,

Massachusetts, USA

${ }^{5}$ Department of Epidemiology, College of Public Health, University of lowa, lowa City, Iowa, USA

${ }^{6}$ Division of Epidemiology of Chronic Diseases and Vulnerable Populations, Department of Quantitative Health Sciences, University of Massachusetts Medical School, Worcester, Massachusetts, USA

${ }^{7}$ Department of Medicine, Stanford University School of Medicine, Stanford, California, USA

${ }^{8}$ MedStar Health Research Institute, Hyattsville, Maryland, USA

${ }^{9}$ Georgetown and Howard Universities Center for Clinical and Translational Science, Washington, District of Columbia, USA

Contributors NIP conceived of the idea, designed the study, interpreted the analysis, drafted and critically reviewed the manuscript. She provided final approval of the manuscript. KK and $\mathrm{HH}$ conducted study design, statistical analysis and 
critical review of the manuscript. They provided final approval of the manuscript. JEO, MAA, JWM, KRR, MEW and MVP assisted with study design, analysis interpretation, drafting and critical reviewed the manuscript. They provided final approval of the manuscript. BVH assisted with study design, interpreted the analysis, drafted and critically reviewed the manuscript. They provided final approval of the manuscript.

Funding This work was supported by AHA grant 13CRP17350002 (NIP), NIH grants 7R21HL115398 (NIP), KL2TR000160 (MEW) and U01HL105268 (MEW), NHLBI/ NIH \& DHHS through contracts, HHSN268201100046C, HHSN268201100001C, HHSN268201100002C, HHSN268201100003C, HHSN268201100004C.

Competing interests None declared.

Patient consent Not required.

Ethics approval IRB of University of California San Francisco.

Provenance and peer review Not commissioned; externally peer reviewed.

Data sharing statement This was a secondary analysis of pre-existing data and as such, no new data were generated by this study. Information about data sharing for the Women's Health Initiative can be found at the following website: https:// www.whi.org/researchers/data/Pages/Home.aspx

Open access This is an open access article distributed in accordance with the Creative Commons Attribution Non Commercial (CC BY-NC 4.0) license, which permits others to distribute, remix, adapt, build upon this work non-commercially, and license their derivative works on different terms, provided the original work is properly cited, appropriate credit is given, any changes made indicated, and the use is non-commercial. See: http://creativecommons.org/licenses/by-nc/4.0/.

\section{REFERENCES}

1. Cheng S, et al. Long-term Outcomes in Individuals With Prolonged PR Interval or First-Degree Atrioventricular Block. JAMA 2009;301:2571-7.

2. Magnani JW, Williamson MA, Ellinor PT, et al. P wave indices: current status and future directions in epidemiology, clinical, and research applications. Circ Arrhythm Electrophysiol 2009;2:72-9.

3. Cuspidi C, Rescaldani M, Sala C. Prevalence of echocardiographic left-atrial enlargement in hypertension: a systematic review of recent clinical studies. Am J Hypertens 2013;26:456-64.

4. Yaghi S, Moon YP, Mora-McLaughlin C, et al. Left atrial enlargement and stroke recurrence: the northern Manhattan stroke study. Stroke; a journal of cerebral circulation 2015;46:1488-93.

5. Pérez-Riera AR, de Abreu LC, Barbosa-Barros R, et al. Baranchuk A. P-wave dispersion: an update. Indian Pacing and Electrophysiology Journal 2016;16:126-33.

6. Baumert M, Seeck A, Faber R, et al. Longitudinal changes in QT interval variability and rate adaptation in pregnancies with normal and abnormal uterine perfusion. Hypertension Research 2010;33:555-60.

7. Lechmanova M, Kittnar O, Mlcek M, et al. QT dispersion and T-loop morphology in late pregnancy and after delivery. Physiological research / Academia Scientiarum Bohemoslovaca 2002;51:121-9.

8. Burchfield JS, Xie M, Hill JA. Pathological Ventricular Remodeling: Mechanisms: Part 1 of 2. Circulation 2013;128:388-400.
9. Parikh NI, Lloyd-Jones DM, Ning $\mathrm{H}$, et al. Association of number of live births with left ventricular structure and function. The Multi-Ethnic Study of Atherosclerosis (MESA). Am Heart J 2012;163:470-6.

10. Sedlak T, Shufelt C, Iribarren C, et al. Sex Hormones and the QT Interval: A Review. J Womens Health 2012:4:4.

11. Kadish $\mathrm{AH}$, Greenland $\mathrm{P}$, Limacher MC, et al. Estrogen and Progestin Use and the QT Interval in Postmenopausal Women. Annals of Noninvasive Electrocardiology 2004;9:366-74.

12. Design of the Women's Health Initiative clinical trial and observational study. The Women's Health Initiative Study Group. Controlled clinical trials 1998;19:61-109.

13. Hays J, Hunt JR, Hubbell FA, et al. The women's health initiative recruitment methods and results. Ann Epidemiol 2003;13:S18-S77.

14. Rossouw JE, Anderson GL, Prentice RL, et al. Risks and benefits of estrogen plus progestin in healthy postmenopausal women: principal results From the Women's Health Initiative randomized controlled trial. JAMA: The Journal of the American Medical Association 2002;288:321-33.

15. Chobanian AV, Bakris GL, Black HR, et al. The Seventh Report of the Joint National Committee on Prevention, Detection, Evaluation, and Treatment of High Blood Pressure: the JNC 7 report. JAMA 2003;289:2560-72.

16. Rautaharju PM, Kooperberg C, Larson JC, LaCroix A. Electrocardiographic Abnormalities That Predict Coronary Heart Disease Events and Mortality in Postmenopausal Women: The Women's Health Initiative. Circulation 2006;113:473-80.

17. Bobrow KL, Quigley MA, Green J, et al. Persistent effects of women's parity and breastfeeding patterns on their body mass index: results from the Million Women Study. Int J Obes 2013;37:712-7.

18. Vaidya D, Bennett WL, Sibley CT, et al. Association of Parity With Carotid Diameter and Distensibility: Multi-Ethnic Study of Atherosclerosis. Hypertension 2014;64:253-8.

19. Giubertoni E, Bertelli L, Bartolacelli Y, et al. Parity as predictor of early hypertension during menopausal transition. J Hypertens 2013;31:501-7. discussion 7.

20. Magnani JW, Johnson VM, Sullivan LM, et al. P-wave indices: derivation of reference values from the Framingham Heart Study. Ann Noninvasive Electrocardiol 2010;15:344-52.

21. Simmons LA, Gillin AG, Jeremy RW. Structural and functional changes in left ventricle during normotensive and preeclamptic pregnancy. Am J Physiol Heart Circ Physiol 2002;283:H1627-H1633.

22. Ouzounian JG, Elkayam U. Physiologic changes during normal pregnancy and delivery. Cardiol Clin 2012;30:317-29.

23. Ozmen N, Cebeci BS, Yiginer O, et al. P-wave dispersion is increased in pregnancy due to shortening of minimum duration of $P$ : does this have clinical significance? J Int Med Res 2006;34:468-74.

24. Karabag T, Hanci V, Aydin M, et al. Influence of Menstrual Cycle on $P$ Wave Dispersion. Int Heart J 2011;52:23-6.

25. Mueller NT, Pereira MA, Demerath EW, et al. Earlier menarche is associated with fatty liver and abdominal ectopic fat in midlife, independent of young adult BMI: The CARDIA study. Obesity 2015;23:468-74.

26. Janghorbani M, Mansourian M, Hosseini E. Systematic review and meta-analysis of age at menarche and risk of type 2 diabetes. Acta Diabetol 2014;51:519-28.

27. McManus DD, Xanthakis V, Sullivan LM, et al. Longitudinal tracking of left atrial diameter over the adult life course: Clinical correlates in the community. Circulation 2010;121:667-74.

28. Sedlak T, Shufelt C, Iribarren C, et al. Sex hormones and the QT interval: a review. J Womens Health 2012;21:933-41. 